\title{
Anesthesia Issues and Challenges: An African Perspective
}

\author{
Faisal Muhammad (iD) ${ }^{1,2, *}$ \\ ${ }^{1}$ Department of Public Health, Faculty of Allied Health Sciences, Daffodil International University, Dhaka, Bangladesh \\ ${ }^{2}$ Department of Social Work, School of Liberal Arts \& Social Sciences, University of Information Technology and Sciences, Dhaka, Bangladesh \\ "Corresponding author: B.Sc, MPH, MSS, Research Associate, Deptartment of Public Health, Daffodil International University (DIU), 102 \& 102/1 Shukrabad, Mirpur Rd., \\ Dhanmondi, Dhaka-1207, Bangladesh. Tel: +880-1723406483, Email: fokkanya@yahoo.com \\ Received 2020 May 09; Revised 2020 May 18; Accepted 2020 May 21.
}

Keywords: Anesthesia, Healthcare, Maternal, Hospital, Africa

\section{Dear Editor,}

There is an international standard for safe practice of anesthesia for the professional anesthesiologist which has been recommended by the society of anesthesiologists; with the aim of providing guidance and assistance to anesthesia professionals, in order to maintain the quality and safety of anesthesia care across the globe (1). Anesthesia complications were identified as a significant risk factors of a maternal mortality (543 per 100,000) after caesarean delivery among 22 African countries (2). Another study from Nigeria reported that anesthetics complications contributed to the morality of patients (3). However there's no clear evidence that says the level of anesthesia provider has contributed directly to the maternal mortality. Some anesthesia complications are expected to be as a result of inadequate training and skills. A reasonably good outcome was reported among neonates' patients ( 136 neonates were discharged out of 190); and it was found that the outcome was due to involvement of senior residents in anesthesia. In Africa most of young medical graduates found anesthesia specialty unattractive. A study among 105 graduating medical students was conducted in Nigeria and only $3 \%$ of them were interested in anaesthesia specialization. A survey conducted in Uganda reported that only little above onetenths of anaesthesia providers could provide safe anesthesia for children $(4,5)$.

In Africa cardiac surgery is not widely available and even where is available the surgery is performed in small numbers as a result of financial constraints and shortage of human resources. As of 2017 the ratio of cardiac centers in Africa is 1 per 33 million (6). To the best of my knowledge, the information (number or ratio) regarding cardiac anesthesia/anesthesiologist in Africa is limited or not known. In Africa most of anesthetics are provided by nonphysicians (UNICEF in 2012 reported 93\% in Uganda, 83\% in Kenya, 95\% in Tanzania, and 96\% in Rwanda). Generally African countries lack institutions for training of physician anesthetists; for example Ghana has only one training in- stitution for physician anesthetists (7). Some African countries have only two or three physician anesthetists for populations of more than 5 million. In Africa there's scarcity of both the personnel and equipment needed to provide safe and quality anesthetic care. There is a need to increase the number of physician anesthetists and improve the training of non-physician anesthesia providers.

\section{Footnotes}

Conflict of Interests: The author have no conflict of interest.

Funding/Support: The author have no funding/support.

\section{References}

1. Merry AF, Cooper JB, Soyannwo O, Wilson IH, Eichhorn JH. International Standards for a Safe Practice of Anesthesia 2010. Can J Anaesth. 2010;57(11):1027-34. doi: 10.1007/s12630-010-9381-6. [PubMed: 20857254]. [PubMed Central: PMC2957572].

2. Bishop D, Dyer RA, Maswime S, Rodseth RN, van Dyk D, Kluyts HL, et al. Maternal and neonatal outcomes after caesarean delivery in the African Surgical Outcomes Study: a 7-day prospective observational cohort study. Lancet Glob Health. 2019;7(4):e513-22. doi: 10.1016/S2214109X(19)30036-1. [PubMed: 30879511].

3. Ekenze SO, Ikechukwu RN, Oparaocha DC. Surgically correctable congenital anomalies: prospective analysis of management problems and outcome in a developing country. J Trop Pediatr. 2006;52(2):12631. doi: 10.1093/tropej/fmi078. [PubMed: 16169860].

4. Edem B, Edentekhe T, Kalu Q, Oku O, Oku A. Specialty choices among graduating medical students in University of Calabar, Nigeria: implications for anesthesia practice. Ain-Shams Journal of Anaesthesiology. 2014;7(4):485. doi: 10.4103/1687-7934.145673.

5. Hodges SC, Mijumbi C, Okello M, McCormick BA, Walker IA, Wilson IH. Anaesthesia services in developing countries: defining the problems. Anaesthesia. 2007;62(1):4-11. doi: 10.1111/j.1365-2044.2006.04907.x. [PubMed: 17156220].

6. Watkins DA, Johnson CO, Colquhoun SM, Karthikeyan G, Beaton A, Bukhman G, et al. Global, Regional, and National Burden of Rheumatic Heart Disease, 1990-2015. N Engl J Med. 2017;377(8):713-22. doi: 10.1056/NEJMoa1603693. [PubMed: 28834488].

7. Soyannwo OA, Elegbe EO. Anaesthetic manpower development in West Africa. Afr J Med Med Sci. 1999;28(3-4):163-5. [PubMed: 11205823]. 